\title{
Patient Safety in a Pediatric Centre: Partnering with Families
}

\author{
Bonnie Fleming-Carroll, Anne Matlow, Siobhan Dooley, Valerie McDonald, \\ Kimberley Meighan and Kim Streitenberger
}

\begin{abstract}
Patient Centred Care (PCC) is a recognized pillar of quality healthcare. According to the Institute of Medicine (Kohn et al. 2000), PCC respects and is responsive to individual patient preferences, needs and values, and ensures they guide all clinical decisions. In a pediatric setting, both the child and family's preferences and values are critical; as a result, the concept of PCC is broadened to include the entire family, and is termed Family Centred Care (FCC). True FCC requires transparent and ongoing collaboration between the child, family, and all members of the healthcare team.

An institution's commitment to Family Centred Care must be explicit and permeate all aspects of healthcare provisions. At Toronto's Hospital for Sick Children (SickKids), the Families as Partners in Patient Safety Committee has proven to be a successful initiative based on Family Centred Care principles. This interdisciplinary committee includes healthcare providers, parents and representatives from our hospital's Children's Council. The mandate of the group is to: (1) identify patient safety (PS) issues, (2) make recommendations to improve PS and (3) increase awareness and promote the partnership between parents and staff in PS. Key initiatives to date include developing PS information for families, a combined hand hygiene campaign and a campaign
\end{abstract}

to make the hospital $100 \%$ smoke-free. A task-oriented partnership between families and healthcare workers has proven to be a productive model for advancing pediatric patient safety.

\section{Introduction}

Enhancing patient safety in healthcare settings has been attaining much-deserved attention from both healthcare consumers and providers. Both the US report To Err Is Human: Building a Safer Health System (Kohn 2000) and the Canadian report Building a Safer System: A National Integrated Strategy for Improving Patient Safety in Canadian Health Care (National Steering Committee on Patient Safety 2002) served as calls to action to make systemwide changes in order to improve patient safety.

In a healthcare environment focused on caring for acute and chronically ill children, ensuring safety takes on a particularly important role. Both patient factors (including developmental change, dependency on adults, different disease epidemiology and demographic characteristics) and healthcare provider factors can contribute to vulnerabilities in pediatric care. Patient complexity, clinical specialization, rapidly advancing technology and unique issues such as entanglement with equipment and accidental falls further add to the challenge. Furthermore, depending on their developmental stage or level, children may 
not be capable of bringing risk to the attention of healthcare providers, therefore removing an important defence against error. These considerations make it not only intuitive to involve children and families in developing a patient safety culture in pediatrics, but essential.

From the few published studies reporting the incidence of adverse events (AE) in hospitalized children, AE rates appear lower in children than in adults. Retrospective data from chart review and administrative databases suggest that the overall rate of AEs is approximately one per 100 discharges (Woods et al. 2005; Miller et al. 2003; Miller and Zhan 2004). However, given the limitations of retrospective methodologies, the rates of AEs in hospitalized children are likely much higher. More recently, two prospective studies, focusing on adverse drug events (ADEs) alone, have reported an $\mathrm{ADE}$ rate of 2.3 to 6 per 100 admissions, with a potential $\mathrm{ADE}$ rate up to 10 per 100 admissions (Kaushal et al. 2001; Holdsworth et al. 2003). Applying trigger tool methodology to the pediatric population may further reveal the true incidence of AEs in pediatrics (Matlow et al. 2005).

In response to the need for safe care of children, SickKids developed a Blueprint for Safety (Stevens et al. 2005) made up of 10 key components: leadership and culture; management of critical occurrences; external surveillance; internal surveillance; policies, procedures and guidelines; staff education; partnering with patients and families; program coordination; proactive risk assessments and audits; and evaluation and research. This paper explores a strategic action-based initiative that highlights children and families as key stakeholders in safety. While addressing some of the above components, the Families as Partners in Patient Safety Committee emphasizes the partnership between healthcare providers and children and families in ensuring safe care.

\section{Family Centred Care and Patient Safety}

Patient Centred Care (PCC) has been identified as a key component to delivering safer care (Kohn et al. 2000). In pediatrics, the concept has been expanded to include the family, as each child exists within the family system. The importance of involving patients and families as partners in healthcare is underscored by a recent publication from the Joint Commission on Accreditation of Healthcare Organizations, entitled Patients as Partners: How to Involve Patients and Families in Their Own Care (JCAHO 2006). This publication and others have highlighted the positive impact Family Centred Care has on patient safety (Berntsen 2006; Uhlig et al. 2002). At SickKids, the philosophy of Family Centred Care has influenced policy, strengthened programs, aided in facility design and helped shape day-to-day interactions among children, families and healthcare providers (Chenery 2004). There is an accepted understanding of the family as the child's primary source of strength and support, and the child and family's perspectives and information are valued in clinical decision-making (Franck and Callery 2004). Family Centred Care is threaded throughout the processes of patient care, education and research, as well as across broader hospital systems. Individual practitioners collaborate with children and families on a daily basis to share information, formulate mutual goals and partner in care. On a systems level, families are integrated into training for healthcare providers, organizational strategic planning and hospital committees. This broad application of Family Centred Care principles facilitates the integration of the child and family as collaborative partners at all levels of the healthcare team (MacKean 2005).

Integration of Family Centred Care across the organization complements our commitment to patient safety. Parents have a vested interest in helping healthcare providers make sure their children are cared for in a safe environment. Partnering with families about patient safety has highlighted the families' role in educating staff and also increased the lines of defence against error. Through this initiative, SickKids has reinforced its commitment to Family Centred Care and actively embarked on building a culture of safety through collaboration and partnership.

\section{Families as Partners in Patient Safety Committee}

Children and families have insights that are unique and are critical to successfully moving initiatives forward. SickKids has embarked on a partnership with families to ensure the safety of their children through the Families as Partners in Patient Safety Committee. The committee was established to provide leadership in supporting and promoting the partnership between families and healthcare professionals. This interprofessional committee includes healthcare professionals, parents and representatives from the hospital's Children's Council. Having family members and a Children's Council representative on the committee has enhanced the dialogue and supported a shift toward implementing a shared culture of patient safety (Berntsen 2006; Ponte et al. 2004).

The need for interprofessional representation on the committee is also essential for positively influencing patient safety culture and quality of care. Patient safety can be a sensitive topic for professionals; it is essential that the committee structure allow a safe environment in which all members feel comfortable to communicate and share safety concerns, supported by leadership that fosters openness and communication free of blame (Ponte et al. 2004).

The mandate of the committee includes: (1) identifying patient safety issues and potential contributing factors, (2) making recommendations for strategies that may include policies/procedures/frameworks to improve patient safety, (3) implementing change and evaluating the outcome in improving patient safety, (4) developing communication strategies for increasing the awareness of and for promoting the partner- 
ship between families and staff in patient safety and (5) sharing leading practices locally, nationally and internationally.

\section{Safety Initiative Highlights}

The committee remains committed to action-oriented initiatives. In addition to brainstorming around the committee table, we sought the input of our Children's Council on issues they considered to be of concern from a patient perspective. Their suggestions are outlined in Table 1.

The following are four of the current priorities our committee identified and tackled (see Table 2 for details):

\section{Patient Safety Information for Families}

Recognizing the important role patients can play at each stage in their care, the Ontario Hospital Association (OHA) recently developed a provincial patient safety initiative entitled "Your
Table 1. Patient safety suggestions from the Children's Council

- Make sure playrooms are safe in both in- and outpatient areas

- Make sure kids in infectious diseases clinic follow infection control precautions

- Have a key for the closets in the patient rooms that you sign out from the front desk to use while you are here to keep your stuff safe

- Lockers for families with a padlock like you would have at a fitness gym

- Check on kids who are alone in inpatient rooms frequently to make sure they are safe

- Make sure little kids cannot strangle on I.V. tubing

- Improve the lighting in the parking garage

- Escort service with security for the parking garage

- Cars double parked/stopped on the driveway makes it unsafe

- No smoking on property and especially around the entrances to the hospital

Table 2. Families as partners in patient safety: current and future initiatives

\begin{tabular}{|c|c|c|c|}
\hline Initiatives & Rationale & Strategies & Next Steps \\
\hline $\begin{array}{l}\text { OHA pamphlets } \\
\text { Sick Kids pediatric focused } \\
\text { information for families }\end{array}$ & $\begin{array}{l}\text { To support families in becoming } \\
\text { safety advocates for their children } \\
\text { To utilize families as a partner in } \\
\text { ensuring safe care } \\
\text { To positively affect pediatric safety } \\
\text { broadly }\end{array}$ & $\begin{array}{l}\text { Market OHA brochure internally: posters } \\
\text { throughout hospital in multiple languages } \\
\text { Paper copies available } \\
\text { Link on Sick Kids website to OHA website } \\
\text { Pamphlet in multiple languages } \\
\text { Development and production of a pediatric- } \\
\text { specific safety pamphlet to complement OHA } \\
\text { material } \\
\text { Advocate for OHA to develop a pediatric } \\
\text { version to address needs outside of Sick Kids }\end{array}$ & $\begin{array}{l}\text { Distribution of new pediatric safety } \\
\text { pamphlet with hospital family guide- } \\
\text { book } \\
\text { Development of risk reporting system } \\
\text { for children and families (CCU pilot) } \\
\text { Development of Welcome to a Sick } \\
\text { Kids Committee pamphlet for new } \\
\text { family members to support them in } \\
\text { their role as committee members }\end{array}$ \\
\hline Hand hygiene campaign & $\begin{array}{l}\text { To identify safety concerns that } \\
\text { broadly affect all or most clinical } \\
\text { settings } \\
\text { To identify safety concerns for } \\
\text { which parents and children can } \\
\text { partner with healthcare providers } \\
\text { to improve care on an ongoing } \\
\text { basis }\end{array}$ & $\begin{array}{l}\text { Mobile cart developed with patient and } \\
\text { family education materials and activities to } \\
\text { heighten awareness of importance of hand } \\
\text { washing }\end{array}$ & $\begin{array}{l}\text { Proposed stationary handwashing } \\
\text { booth scheduled for fall } 2006 \text { in high } \\
\text { traffic area } \\
\text { Evaluation-audits, satisfaction ques- } \\
\text { tionnaires } \\
\text { Investigate safety concerns of } \\
\text { "Heelies" - shoes with wheels }\end{array}$ \\
\hline Smoke-free hospital & $\begin{array}{l}\text { To identify organizational/system } \\
\text { changes that support the safety of } \\
\text { children and families }\end{array}$ & $\begin{array}{l}\text { Compelling signage } \\
\text { Letter to parents explaining reason for } \\
\text { change } \\
\text { Letter to staff explaining reason for change } \\
\text { Patrolling by security staff support effective } \\
\text { Communication for security staff }\end{array}$ & $\begin{array}{l}\text { Advocate painted boundaries on side- } \\
\text { walk around hospital property } \\
\text { Compliance audits } \\
\text { Advocate regular monitoring of } \\
\text { grounds } \\
\text { Continued awareness campaign } \\
\text { through hospital communication } \\
\text { systems } \\
\text { Looking into effect of smoke on } \\
\text { clothing of staff - possible uniform } \\
\text { policy change }\end{array}$ \\
\hline $\begin{array}{l}\text { Patient safety } \\
\text { Sharing knowledge } \\
\text { International conference } \\
\text { Speakers } \\
\text { Written materials } \\
\text { Research }\end{array}$ & $\begin{array}{l}\text { To promote knowledge transfer } \\
\text { locally, nationally and internation- } \\
\text { ally }\end{array}$ & $\begin{array}{l}\text { 1st Annual Safety Conference (2005) } \\
\text { 2nd Annual Safety Conference (2006) } \\
\text { Hospital-wide patient safety rounds held } \\
\text { Regularly invited speakers } \\
\text { Partners in Patient Safety newsletter }\end{array}$ & $\begin{array}{l}\text { Education for staff acknowledging } \\
\text { our need and expectation for families } \\
\text { to speak up about safety - integrate } \\
\text { a safety talk into orientation of new } \\
\text { staff; use our communication tools, } \\
\text { i.e., safety newsletter }\end{array}$ \\
\hline
\end{tabular}


Health Care - Be Involved" (OHA 2004). This initiative includes multilingual informational pamphlets, posters and multimedia presentations for patients designed to empower them to become more active in their healthcare. An implementation tool kit was distributed to hospitals throughout the province, and the posters and pamphlets were made available at key entry points to the hospital. The committee reviewed the material to ensure applicability in the pediatric setting. A patient safety section was established on our hospital's website where patients and families and healthcare providers could easily access the pamphlets in a variety of languages as well as the multimedia presentation. During the hospital-wide implementation of the initiative, our committee identified the need to develop information and tools specifically designed to focus on the unique needs of pediatric patients and families (e.g., using simpler language, targeting substitute decision makers, advising on unique aspects of pediatric medication safety, having childfriendly graphics, etc). The group worked collaboratively with a variety of internal stakeholders including the Children's Council, the Family Advisory Council and interdisciplinary healthcare professionals to develop a pediatric-specific safety informational pamphlet for use at SickKids that would supplement the provincial program. Through our advocacy concerning the uniqueness of child safety issues, discussion is currently under way at OHA to develop pediatric-specific resources to meet the needs of children and families throughout the province.

\section{Hand Hygiene Campaign}

The importance of hand hygiene in preventing infection has recently been underscored by the World Health Organization's World Alliance for Patient Safety, which includes hand hygiene as one of its initiatives (Pittet and Donaldson 2006). Interest in improving hand hygiene practices at SickKids was generated following a presentation made by Infection Prevention and Control to the committee. As well, handwashing practices were identified as inconsistent by our parent representatives. An interdisciplinary task force was formed to develop a unique approach to improve hand hygiene compliance by engaging patients and families as part of a multimodal approach to improvement. The concept involves a mobile cart, the "Bug Buggy," which is taken to areas of the hospital with high volumes of patient activity where patients and families can engage in a variety of learning activities - with printed information, DVDs, books and other products - related to hand hygiene. Trained volunteers are present to provide information and to supervise the activities. In addition to raising awareness and educating patients, families and visitors about hand hygiene, the new culture is intended to empower patients and families to articulate their expectations about it.

Once the program has been fully implemented, it will be evaluated through patient and family satisfaction surveys, by the volume of access to the cart materials and by ongoing hand hygiene practice audits performed by the Infection Prevention and Control Program.

\section{No Smoking on Hospital Property}

In 2006, the Families as Partners in Patient Safety Committee recommended to the hospital's executive team a change in smoking policy, and an extension of the hospital's no-smoking zone to include the entire property. The recommendation was made after extensive discussion with parents and patients expressing concerns about second-hand smoke at hospital entrances and other areas of hospital grounds. The executive endorsed the committee's recommendation and revised its policy, effective May 1, 2006. The committee was also instrumental in developing the policy's marketing campaign, which involved compelling signage designed by parents that included children's faces and written information for parents and staff. The committee felt the campaign would be effective if the focus of the smoke-free environment was the health of all vulnerable children.

We are working to integrate an education program to assist security personnel to sensitively approach staff and families and to direct them to where they can smoke. We are negotiating routine patrolling of the grounds. Our next step is to complete audits to determine rates of noncompliance, which is slated to start within the next three months.

\section{Sharing Patient Safety Knowledge}

Espousing and promoting the values of Family Centred Care has been a key determinant in designing and hosting an annual pediatric patient safety symposium. The initial symposium entitled "Partners in Pediatric Patient Safety: Taking Care of the Kids" was held in June 2005. The opening talk was delivered by a family member who had lost a child through medical error (Keatings et al. in press), setting the stage for further presentations describing strategies required and efforts currently under way to create a culture of safety for children. Workshops included those dedicated to cultural diversity and transitions in care.

This year's symposium was entitled "Partners in Pediatric Patient Safety: Solutions and Perspectives from Around the World." Pediatric Patient Safety experts were convened from Australia, the UK, the US and Canada, providing a global look at key patient safety issues including the nature of a culture of safety, information technology solutions, hospital-acquired infections and learning from critical occurrences. One module was devoted specifically to issues involving the family as partners, and included a talk on cultural and linguistic competence, simulation as an aid to improving provider-family communication, and a talk by a family member of the Families as Partners in Patient Safety Committee, promoting the committee as a model of working together. 


\section{Overcoming Barriers to Integrating Children and Families}

One of the most difficult barriers to integrating parents and children into our safety initiatives has been scheduling issues. The majority of parents work, and children have school commitments that do not allow much flexibility for involvement. We have tried to be flexible by scheduling meetings in the middle of the day in order for parents to get their children to and from school, or in the early evening. We have supplied family members with parking passes to alleviate the cost of parking. We also utilize e-mail in order to communicate and get feedback in a timely manner. Children's voices are also heard through a representative from our Child Life, who sits on the hospital's Children's Council and the Families as Partners in Patient Safety Committee to act as a liaison representing the children's perspective.

In recruiting parent representatives, we have found that targeting parents in specific clinical areas seems to be successful. Having a relationship with the family helps when approaching a parent. We also try to prioritize the committees for which families would have the most impact. Recruiting parent members who were also members of the Family Advisory Committee is useful, since they come with an understanding of their role as parents on a committee. Future developments include an orientation pamphlet to address committee membership to help welcome and socialize parents into the group.

Another barrier to involvement has been the inability for family members to access our computerized risk reporting system. Currently, this can only be used by hospital staff for real-time risk reporting. Parent members felt strongly that there needed to be a way for parents to identify safety issues in real time. In order to address this, we are piloting a safety suggestion box in the Critical Care Unit to see if this is an effective way to capture parent feedback, which can be anonymous if desired.

We have continued to strengthen the commitment to safety by aligning the work of the committee to our strategic directions. Safety is a major priority of the hospital, and this is evident by the new reporting structure that links the committee directly to the executive.

\section{Conclusions}

The Families as Partners in Patient Safety Committee has been a model of "teamwork" around the committee table, focused on improving patient care. Our committee has become a driving force for patient safety initiatives and has contributed to building a safety culture. Discussions between staff and families have allowed risk issues to surface and proactive strategies to begin. The committee members seek and encourage participation in the development and implementation of select initiatives. This networking across the organization has facilitated organizational expectations and attitudes regarding patient safety.
Collaborating with families as partners has helped build trusting relationships. Not only are the family members on the committee a part of the system of safety, but the goal is to welcome all families at the hospital as safety advocates. Future directions include encouraging families to identify safety issues in real time through "Safety Cards" they can fill out and deposit in boxes on each unit, involving children and families in actively reminding staff to kindly wash their hands before engaging in patient care, and focusing on educating staff on how to communicate and collaborate with children and families who identify safety issues directly. The Families as Partners in Patient Safety Committee is an innovative approach to creating a system of safety in a high-risk pediatric environment. One parent committee member states, "This exceptionally productive committee is a stellar example of effective family, staff and patient collaboration. ... the combined perspective of the different members provides a very comprehensive approach to improving patient safety."

\section{About the Authors}

Bonnie Fleming-Carroll, MN, ACNP, is an Acute Care Nurse Practitioner leading the advancement of Family Centred Care at the Hospital for Sick Children through her role as Family Centred Care Senior Consultant. She is also the Interim Director of Nursing Education at the hospital.

Anne Matlow, MD, FRCPC, is Medical Director of Patient Safety at SickKids and was the first Chair of the Families as Partners in Patient Safety Committee.

Siobhan Dooley, BA, is a communications specialist at SickKids. She sits on the committee and is instrumental in facilitating our internal communications.

Valerie McDonald is the co-chair of the Family Advisory Council and a parent member of the Families as Partners in Patient Safety Committee.

Kimberley Meighan, RN, is the Manager of the AboutKidsHealth Resource Centre for Families, which is located in the hospital. She works closely with Safe Kids Canada in promoting children's safety internally and externally.

Kim Streitenberger, RN, is a Quality Analyst at SickKids and a member of the committee. She was instrumental in making the OHA safety material available to our families.

Please direct correspondence to: Bonnie Fleming-Carroll, Centre for Nursing, Hospital for Sick Children, 555 University Avenue, Toronto, ON M5G 1X8. Tel: 416-813-8201. Fax: 416813-8273. E-mail: bonnie.fleming-carroll@sickkids.ca.

\section{Acknowledgments}

Thanks go to Rick Wray, RN, an Infection Control Practitioner at SickKids who has championed the handwashing campaign within the hospital, and to Margaret Keatings, RN, MHSc, Chief Nursing Officer and VP of Professional Services at SickKids, who has been extremely supportive as the executive sponsor and member of the committee. 
We also wish to thank other members of the Families as Partners in Patient Safety Committee: Judy Burns, Sydney Cameron, Nancy Cornish, Jane Darch, Jane Ford, Cheryl Harris, Margaret Keatings, Barbara Neilson and Polly Stevens.

\section{References}

Berntsen, K.J. 2006. "Implementation of Patient Centeredness to Enhance Patient Safety.” Journal of Nursing Care Quality 21(1): 1519.

Chenery, K. 2004. "Understanding Our Past: Nursing Praxis in New Zealand." Family-Centred Care 20(3): 4-11.

Committee on Quality of Health Care in America. 2001. Crossing the Quality Chasm: A New Health System for the 21st Century. Washington, DC: National Academy Press, Institute of Medicine.

Franck, L.S. and P. Callery. 2004. "Re-thinking Family-Centred Care across the Continuum of Children's Healthcare." Child: Care, Health \& Development 30(3): 265-77.

Holdsworth, M.T., R.E. Fichtl, M. Behta, D.W. Raisch, E. MendezRico, A. Adams, M. Greifer, S. Bostwick and B.M. Greenwald. 2003. "Incidence and Impact of Adverse Drug Events in Pediatric Inpatients." Archives of Pediatrics \& Adolescent Medicine 157: 60-65.

Joint Commission Resources. 2006. "Patients as Partners: How to Involve Patients and Families in Their Own Care." Oakbrook Terrace, IL.

Kaushal, R., D.W. Bates, C. Landrigan, K.J. McKenna, M.D. Clapp, F. Federico and D.A. Goldmann. 2001. "Medication Errors and Adverse Drug Events in Pediatric Inpatients." Journal of the American Medical Association 285: 2114-20.

Keatings, M., J. Lewis and M. Martin. In press. "Patient Safety: Learning from Disclosure of Medical Error." Pediatric Clinics of North America.

Kohn, L.T., J.M. Corrigan and M.S. Donaldson (Eds.). 2000. To Err Is Human: Building a Safer Health System. Washington, DC: National Academy Press, Committee on Quality of Health Care in America, Institute of Medicine.
MacKean, G., W.E. Thurston and C.M. Scott. 2005. "Bridging the Divide between Families and Health Professionals' Perspectives on Family-Centred Care." Health Expectations 8: 74-85.

Matlow, A., V. Flintoft, E. Orrbine, B. Brady-Fryer, C.M. Cronin, C. Nijssen-Jordan, M. Fleming, M.A. Hiltz, M. Lahey, M. Zimmerman and G.R. Baker. 2005. "The Development of the Canadian Pediatric Trigger Tool for Identifying Potential Adverse Events." Healthcare Quarterly 8: 90-99.

Miller, M.R. and C. Zhan. 2004. "Pediatric Patient Safety in Hospitals: A National Picture in 2000." Pediatrics 113: 1741-46.

Miller, M.R., A. Elixhauser and C. Zhan. 2003. "Patient Safety Events during Pediatric Hospitalizations.” Pediatrics 111: 1358-66.

National Steering Committee on Patient Safety. 2002. "Building a Safer System: A National Integrated Strategy for Improving Patient Safety in Canadian Health Care." Royal College of Physicians and Surgeons of Canada site. Retrieved June 14, 2006. <http://rcpsc.medical.org/publications/buildingasafersystem_e.pdf>

Ontario Hospital Association. "Your Health Care: Be Involved." Accessed June, 2006. <http://www.oha.com/client/OHA/ OHA_LP4W_LND_WebStation.nsf/page/Your+Health+Care++ Be+Involved.>

Pittet, D. and L. Donaldson. 2006. "Challenging the World: Patient Safety and Health Care-Associated Infection." International Journal for Quality in Health Care 18: 4-8.

Ponte, P.R., M. Connor, R. De Marco and J. Price. 2004. "Linking Patient and Family-Centered Care and Patient Safety: The Next Leap." Nursing Economics 22(4): 211-15.

Stevens, P., A. Matlow and R. Laxer. 2005. "Building from the Blueprint for Patient Safety at the Hospital for Sick Children." Healthcare Quarterly 8(Special Issue): 132-39.

Uhlig, P.N., J. Brown, A.K. Nason, A. Camelio and E. Kendall. 2002. "John M. Eisenberg Patient Safety Awards. System Innovation: Concord Hospital." Joint Commission Journal on Quality Improvement 28(12): 666-72.

Woods, D., E. Thomas, J. Holl, S. Altman and T. Brennan. 2005. "Adverse Events and Preventable Adverse Events in Children." Pediatrics 115(1): 155-60.

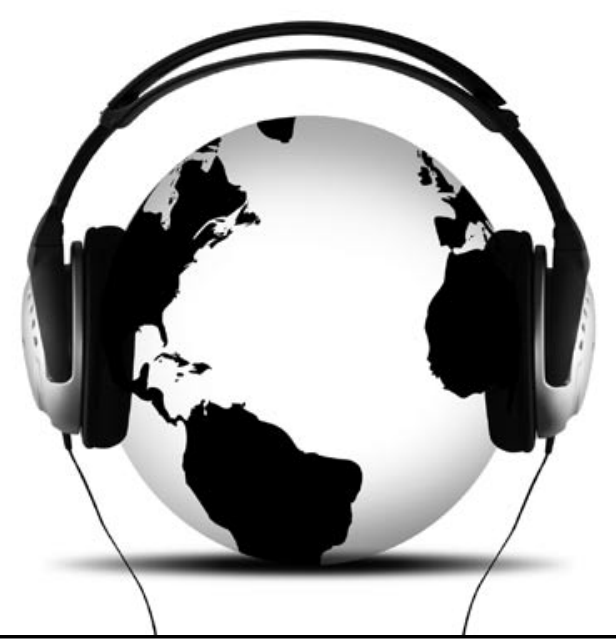

\title{
Ideas worth listening to.
}

\author{
Longwoods Radio available now at \\ www.longwoods.com
}

